\title{
Infliximab in the treatment of rheumatoid arthritis
}

\author{
This article was published in the following Dove Press journal: \\ Biologics: Targets \& Therapy \\ 5 May 2009 \\ Number of times this article has been viewed
}

\section{A Perdriger \\ Service de Rhumatologie, CHU de Rennes, Hôpital sud, France}

Correspondence: Professeur A Perdriger Service de Rhumatologie, $\mathrm{CHU}$ de Rennes, Hôpital sud, 16 boulevard de Bulgarie, 35056 Rennes Cedex, France Tel +33 (02) 99267140

Fax +33 (02) 99267190

Email aleth.perdriger@chu-rennes.fr
Abstract: Infliximab was the first monoclonal antibody to human necrosis factor alpha (TNF $\alpha$ ) developed for treating rheumatoid arthritis (RA). This chimeric antibody binds with high affinity to both soluble and trans-membrane TNF and is able to reduce synovial inflammation, bone resorption and cartilage degradation. The efficacy of infliximab has been observed in active RA despite treatment with multiple disease modifying anti-rheumatic drugs (DMARDs), and in early disease with no prior treatment by methotrexate (MTX). Infliximab has been shown to reduce joint inflammation and to slow radiographic progression, in both clinical and non-clinical responders. Recent data suggest that using infliximab early in RA treatment increases the percentage of clinical remission and allows infliximab discontinuation. The recommended dosage of $3 \mathrm{mg} / \mathrm{kg}$ could be increased up to $10 \mathrm{mg} / \mathrm{kg}$ with partial efficacy of the dose escalation. Antibodies to infliximab have been observed in $7 \%$ to $61 \%$ of patients and are associated with a low trough level of infliximab and secondary response failure. Their occurrence could be prevented by co-medication with MTX. The combination of DMARDs other than MTX with infliximab was found to be safe and efficacious. Infections, principally tuberculosis, are increased in treated patients, and the risk is greater at higher dose. Even if the treatment is generally safe and well tolerated, patients treated with infliximab should be closely monitored.

Keywords: infliximab, rheumatoid arthritis, disease modifying anti-rheumatic drugs

Rheumatoid arthritis (RA) is a chronic disease characterized by an immune mediated inflammatory synovitis leading to joint cartilage and bone destruction. ${ }^{1}$ The inflammatory cells of synovial RA release numerous cytokines, including tumor necrosis factor alpha (TNF $\alpha$ ), interleukin 1 (IL-1) and interleukin 6 (IL-6). ${ }^{2}$ The key factor in inflammation and matrix destruction is TNF $\alpha$, whose level has been found to have a strong relationship with the extent of the synovitis and with erosion in RA joints. ${ }^{3}$ In RA patients, TNF blockade has shown a remarkable efficacy in reducing joint inflammation, slowing radiographic progression of joint damage, and improving physical function. ${ }^{4}$ Today there are three registered TNF antagonists, infliximab, etanercept and adalimumab. Clinical trials are ongoing for two others, certolizumab and golimumab. ${ }^{5}$ Infliximab, initially called cA2, was the first TNF antagonist authorized for the treatment of RA, in 1998 in the US. Infliximab is a chimeric anti-TNF monoclonal antiboby, with murine variable regions and human IgG1 constant region. ${ }^{6}$ This review evaluates the therapeutic use of infliximab in 
RA, summarizing data on its mode of action, efficacy and safety.

\section{What is the place of TNF in the pathogenesis of RA?}

In RA pathogenesis, TNF plays a central role in the pro-inflammatory cytokine cascade. It induces the production of other inflammatory cytokines, such as IL-1 and IL-6; recruits inflammatory cells into the joints, stimulates the expression of adhesion molecules in the synovial endothelium and the secretion of matrix metalloproteinases by chondrocytes and synovial fibroblasts and amplifies bone resorption by promoting osteoclast differentiation., ${ }^{3,7}$

TNF $\alpha$ is released from synovial macrophages as a soluble cytokine ( $\mathrm{sTNF} \alpha$ ), a homotrimer of $17 \mathrm{KDa}$ monomers, after being enzymatically cleaved from its cell surface-bound precursor, the transmembrane TNF $\alpha$ ( $\operatorname{tmTNF} \alpha$ ) by TNF $\alpha$-converting enzyme (TACE). Both sTNF $\alpha$ and tmTNF $\alpha$ are biologically active and interact with either of two distinct receptors, TNFR1 (p55, CD120a) and TNFR2 (p75, CD120b). Both sTNF $\alpha$ and tmTNF $\alpha$ play an important role in the pro-inflammatory functions of TNF $\alpha .{ }^{8}$ Receptor-mediated effects of TNF $\alpha$ can lead alternatively to cell activation or apoptosis, depending on the metabolic stage of the cell. TmTNF $\alpha$ can also receive signals and act as a receptor. ${ }^{9}$ TmTNF $\alpha$ binding by TNFRs or TNF $\alpha$ antagonists can induce a reverse signaling and trigger cell activation, cytokine suppression or apoptosis, depending on the density of tmTNF $\alpha$ expression, and the ability of cross linkage.

TNF antagonist therapy reduces many of the hallmarks of chronic inflammation, such as leukocyte recruitment and the production of inflammatory mediators. ${ }^{7}$ Fixation of sTNF or tmTNF by TNF antagonists can induce two mechanisms of action: blockade of the TNFR-mediated mechanisms and induction of the tmTNF-mediated mechanisms. ${ }^{8}$ Each TNF antagonist is able to bind to STNF and tmTNF. However, the binding affinity of the different TNF blockers for TNF is not the same. Infliximab binds with a high affinity to both the $17 \mathrm{kDa}$ monomer and the $51 \mathrm{kDa}$ trimer forms of sTNF. As a bivalent monoclonal antibody, infliximab binds two sTNF trimers simultaneously which allows multimeric complexes to form. Infliximab can also bind strongly to tmTNF on human cells and stimulate reverse signaling. Binding of tmTNF by infliximab bivalent monoclonal antibody can favor the cross-linkage of tmTNF and cell signal triggering, depending on the density of tmTNF on the cell surface. ${ }^{8}$
TNF blockade in RA joints regulates the action of TNF on three targets: synovial tissue inflammation, bone erosion and cartilage destruction.

The effect of anti-TNF $\alpha$ drugs on the regulation of synovial tissue inflammation and the relative roles of reduced cell influx, apoptosis or cytotoxicity has not yet been clearly elucidated. ${ }^{10,11}$ However, in RA patients, infliximab therapy is quickly followed by a reduction in swollen joint numbers in parallel with a reduction of the cellularity in the inflamed synovial tissue as a consequence of the action of TNF antagonists on cell trafficking. ${ }^{11}$ Apoptosis of synovial infiltrating cells has also been observed, but not in the early stages after infliximab infusion. Complement dependent cytotoxicity (CDC) or antibody-dependent cell-mediated cytotoxicity (ADCC) could also play a role in reducing synovial cellularity. ${ }^{8}$

Another action of infliximab is the regulation of immune responses by restoring the altered regulatory $\mathrm{T}$ (Treg) cell function in RA. ${ }^{12}$ The function of CD4 + CD25 + Treg is the suppression of auto-reactivity and the regulation of immune response. This function is reduced in patients with RA compared to healthy individuals. ${ }^{13}$ Several recent clinical studies have provided evidence that infliximab could restore the capacity of Treg to suppress proinflammatory cytokine secretion by activated $\mathrm{T}$ cells and monocytes in RA patients. ${ }^{14-16}$

The most compelling clinical manifestations of the efficacy of TNF antagonists in RA patients are the slowing and even the complete arrest of bone destruction. ${ }^{6}$ Bone erosion is mediated by osteoclasts, multinucleated cells derived from monocytes-macrophages osteoclast precursors. Osteoclast-mediated bone resorption is promoted by TNF, in synergy with RANKL (Receptor Activator of Nuclear factor Kappa B Ligand). ${ }^{17}$ RANKL is a growth factor for osteoclast lineage cells. ${ }^{18}$ The maturation of the precursors, and the differentiation, activation and survival of osteoclasts, depend greatly on RANKL. RANKL is produced mainly by osteoblasts in healthy individuals and also, in RA patients, by activated $\mathrm{T}$ cells and fibroblast-like synoviocytes. TNF promotes osteoclastogenesis by directly acting on osteoclast lineage cells, but also indirectly, by promoting synovial inflammation and RANKL production. TNF blockade has been shown to decrease osteoclast formation. ${ }^{19,20}$ Infliximab could directly inhibit osteoclast formation and activity in vitro. ${ }^{19}$ Furthermore, infliximab inhibits the expression of RANKL. ${ }^{8}$ Finally, the rapid reduction in synovial macrophage numbers after TNF blockade may help in reducing the numbers of osteoclasts. ${ }^{8}$ 
Cartilage destruction is mediated by matrix metalloproteinases (MMPs) and other enzymes produced by synovial cells and chondrocytes when stimulated by cytokines, such as TNF, IL-1 and IL-6. TNF plays a critical role in the induction of these matrix-degrading enzymes in RA and TNF blockade reduces MMP production. ${ }^{8,20}$

\section{Efficacy of infliximab in RA Data from clinical trials}

Since 1992, infliximab has been used in different clinical trials to assess its efficacy and safety in RA patients with various disease durations. ${ }^{6,21,22}$ In the first infliximab studies, patients had active disease of long duration that had not adequately responded to one or more classical disease modifying anti-rheumatic drugs (DMARDs), more often methotrexate (MTX). Infliximab was administrated as an intravenous infusion with a dosage ranging from 1 to $20 \mathrm{mg} / \mathrm{kg}$, alone or in combination with MTX at a dose of 7.5 to $20 \mathrm{mg} /$ week. These first trials showed that removal of excess TNF using infliximab was efficacious and well tolerated in RA patients and the combination of infliximab with MTX gave a more efficacious and durable response.

The efficacy of infliximab therapy on RA clinical symptoms was assessed in the pivotal ATTRACT (Anti-TNF Trial in Rheumatoid Arthritis with Combination Therapy) trial. ${ }^{23-25}$ This trial enrolled a total of 428 RA patients with active disease despite MTX therapy. The baseline demographic characterization of the trial population indicated that patients suffered from active erosive disease despite treatment with multiple DMARDs (average 3.6 including MTX) over a mean duration of more than 8 years. Patients were randomized into five parallel groups: four groups were treated with infliximab at 3 or $10 \mathrm{mg} / \mathrm{kg}$ every 4 or 8 weeks plus MTX, and the fifth group was given MTX with placebo infusion every 4 weeks. The efficacy of infliximab was evaluated at week 30, based on the ACR20 response, ${ }^{23}$ and at week 54 for joint damage. ${ }^{24}$ The main results indicated that patients receiving infliximab in combination with MTX presented a rapid improvement of their signs and symptoms: ACR20 response criteria were achieved in $50 \%$ of patients receiving infliximab compared with $20 \%$ of patients on placebo. ${ }^{23}$ The radiological data showed a significantly higher rate of bone erosion in patients treated with placebo than those treated with infliximab. ${ }^{24}$ Patients included in ATTRACT continued to receive infliximab and MTX, or MTX alone unblinded during a second-year extension. ${ }^{25}$ The response rates observed during the ATTRACT trial were maintained over 102 weeks. In addition, the infliximab plus MTX regimens resulted in a significantly greater improvement in HAQ and SF-36 physical component summary scores, and a lesser radiological progression. ${ }^{25}$

Efficacy of infliximab was also observed in RA patients with early disease ( $\leq 3$ years) and no prior treatment with MTX, in the ASPIRE (Active controlled Study of Patients receiving infliximab for the treatment of Rheumatoid arthritis of Early onset) study. ${ }^{26}$ This was the largest trial with infliximab, including 1049 patients, randomized into three groups, MTX with placebo or MTX with infliximab (3 or $6 \mathrm{mg} / \mathrm{kg}$ ). Patients were evaluated on the basis of percentage of ACR improvement (ACR-N) from baseline to week 54. At week 54, the median improvements in ACR-N were significantly higher in patients receiving infliximab than in placebo. In the same way, ACR20, ACR50 and ACR70 response rates were significantly higher in infliximab compared with placebo recipients. The infliximab groups showed less radiographic progression than the placebo group. Finally, physical function (assessed by HAQ) improved more in infliximab groups than in the placebo group.

The third large study investigating the efficacy of infliximab in early RA was the BeST study (BeST is a Dutch acronym for "Behandel Strategieën", treatment strategies). ${ }^{27}$ The aim of BeST was to define the best treatment strategy for preventing the outcome of functional ability (as measured by Health Assessement Questionnaire, HAQ) and the radiographic progression in early RA patients. The BeST study combined early introduction of treatment with intensive therapy adjustments based on programmed disease monitoring (every 3 months) using a disease activity score based on 44 joints until low disease activity of RA (defined as a score $<2.4$ ). The BeST study compared four treatment strategies: sequential monotherapy (group 1), step-up combination therapy (group 2), step-down strategy (group 3 and 4) using tapered high dose prednisone, MTX or sulfazalasine (group 3), or infliximab with MTX (group 4). After 2 years of treatment, there was no difference in clinical symptoms between the four groups: the goal of Disease Activity Score (DAS) 44 low activity was reached by more than $75 \%$ of RA patients in each group, and a clinical remission was observed in $40 \%$ to $45 \%$ of RA patients. ${ }^{28}$ Nevertheless, in this population of early RA, the radiographic progression was less important in groups 3 and group 4 than in groups 1 and 2. After 1 year, the median increase in the total Sharp score was 2 in group 1, 2.5 in group 2, 1 in group 3 and 0.5 in group $4 .{ }^{27}$ After 2 years, $40 \%$ of patients in group 1, $34 \%$ in group 2, 20\% in group 3 and $18 \%$ in group 4 had a 
damage radiographic progression greater than the smallest detectable difference. ${ }^{28}$ Of importance, more patients in groups 3 and 4 were able to taper and discontinue drugs of the initial combination therapy, because of a continuous low disease activity. ${ }^{29}$ In group $4,67 \%$ of patients having a DAS $<2.4$ for over 6 month were able to discontinue initial infliximab. The follow up of these patients for 5 years suggested that the remission reached in patients treated early with infliximab could be more sustainable than remission obtained in patients treated with infliximab as a second or more line of treatment. ${ }^{30}$ The importance of early intervention with infliximab in RA has also been highlighted in a Japanese study ${ }^{31}$ which suggests that infliximab treatment in early RA could be advantageous for both achieving clinical remission and for discontinuing infliximab after clinical remission.

\section{Infliximab and structural damage}

The ATTRACT and ASPIRE studies provide evidence that infliximab is capable of slowing down structural joint damage. ${ }^{24-26,32}$ These two studies also provide an opportunity to examine the relationship between inflammation and bone damage. In both studies, infliximab in addition to MTX has shown a remarkable efficacy in preventing radiographic progression, with a similar efficacy in both clinical responders and non-responders. ${ }^{32-34}$ On the other hand, in ASPIRE, MTX was also able to slow down radiographic progression, but only in patients who were in remission after 3 months of treatment. ${ }^{34}$ In clinical non-responders, MTX used in monotherapy led to a markedly worse radiographic progression. These observations are consistent with a direct role of TNF in inflammatory joint destruction. They also support the concept that efficacies against clinical disease and against joint damage could be dissociated from each other in patients treated by TNF antagonists. ${ }^{8}$

The efficacy of infliximab in preventing joint destruction has also been observed with imaging techniques more sensitive than radiography. ${ }^{35-37}$ Evolution of RA synovitis was evaluated by magnetic resonance imaging (MRI) in RA patients treated with MTX, with symptom duration less than 12 months. ${ }^{35,36}$ After 1 year, the combination of MTX plus infliximab was superior to MTX monotherapy for reducing MRI-detected signs of synovitis, bone edema and erosion score. Another study used ultra-sonography in 24 RA patients, with disease duration $<3$ years. ${ }^{37}$ Sonography enabled the evaluation of synovial thickness. This study also showed a significant improvement in the infliximab group compared with placebo.

\section{Infliximab dose adjustement in daily practice}

Infliximab is the only licensed TNF blockade that is administered by infusion, with a dosage adapted to patient weight. The recommended posology for infliximab in RA is $3 \mathrm{mg} / \mathrm{kg}$ given as an intravenous infusion followed by additional $3 \mathrm{mg} / \mathrm{kg}$ infusion doses at 2 and 6 weeks after the first infusion, then every 8 weeks thereafter. Methotrexate should be given in combination with infliximab. One feature of infliximab compared to other anti-TNF blockades is that the dosage can be adjusted in case of insufficient response or secondary response failure. The dose of infliximab can be increased up to $10 \mathrm{mg} / \mathrm{kg}$ or the treatment interval can be decreased to every 4 weeks. ${ }^{24}$ The efficacy of dose or dose frequency adjustments of the infliximab therapies has been reported in literature. ${ }^{38-48}$ In several studies, including a meta-analysis of 8510 RA patients treated by infliximab, $50 \%$ to $60 \%$ of patients required dose escalation. ${ }^{38,42,43}$ The average dose is $5 \mathrm{mg} / \mathrm{kg}$, increasing most rapidly until the end of the first year. ${ }^{38}$ The elapsed time to dose escalations ranged from 128 to 254 days. The dose increase was more frequent than the shortening of interval between infusions ${ }^{42}$ but the reason for this was not clearly explained. It has been hypothesized that patients who flare during the 8-weekly interval eliminate infliximab more rapidly than patients with a constant response pattern and need a interval shorter than 8 weeks. ${ }^{47}$ On the other hand, higher infliximab doses appeared to be more effective than standard $3 \mathrm{mg} / \mathrm{kg}$ dose for patients with severe disease activity. ${ }^{48}$ Nevertheless, efficacy of the dose adjustments was observed, with a range increase of ACR20 response from $27 \%$ to $36 \%$ and an improvement in DAS. The available data support partial effectiveness of the infliximab dose adjustement in case of secondary response failure.

\section{Immunogenicity of infliximab}

Infliximab being a chimeric molecule, human anti-chimeric antibodies (HACA), also called antibodies to infliximab (ATI) may appear. ${ }^{49}$ Trough level assessments of anti- TNF $\alpha$ drugs and measurements of antibodies against these biologicals are among the parameters that best predict the response of individual RA patients. ${ }^{50}$ Several studies have shown that secondary response failure was associated with low trough levels of anti-TNF $\alpha$ biologicals and the development of antibodies against these drugs. ${ }^{49-51}$ Moreover, AT correlate with trough levels of circulating infliximab and subsequently with response failure. ${ }^{50}$

ATI has been demonstrated in $7 \%$ to $61 \%$ of the patients with psoriasis, Crohn's disease and RA. ${ }^{52,53}$ These widely 
diverging incidences of ATI development can be attributed to the varying risk factors for their development and the association with other drugs in the treatment protocols. The schedule of infliximab administration has been reported to influence of ATI development. Loading the infliximab therapy with three infusions at weeks 0,2 and 6 is probably less immunogenic that only one starting dose. Also, maintenance treatment (an infusion every 8 weeks) is generally advised instead of on demand treatment to prevent ATI formation. ${ }^{53}$ The dosage of infliximab ( 3 or $5 \mathrm{mg} / \mathrm{kg}$ ) does not seem to influence the formation of ATI or the development of infusion reactions. However, the low dose of infliximab $(1 \mathrm{mg} / \mathrm{kg})$ used in the first trial was associated with an increased of ATI formation. ${ }^{21}$ Co-medication with immuno-suppressants is thought to reduce the immunogenicity of infliximab. ${ }^{49,52}$ ATI formation was significantly lower in patients co-treated with MTX..$^{54,55}$ Nothing is known about ATI formation in the combination of infliximab with other DMARDs.

\section{Combination of infliximab and DMARDs}

Infliximab has been approved for use only in combination with MTX. This combination reduces immunogenicity and improves efficacy of the TNF blocker. However, combination of infliximab with DMARDs other that MTX has also been reported. ${ }^{56-62}$ The most studied combination is infliximab in association with leflunomide. ${ }^{56-61}$ In the first published studies, with few patients, a high frequency of cutaneous reactions, skin rash and vasculitis was observed, even though the efficacy of such a combination was also reported. ${ }^{56,57}$ Nevertheless, these side effects were not reported in others studies. In open-label or retrospective studies, ${ }^{58,59,61,62}$ good efficacy and no increase in the side effects were observed with such combination. More recently, in a longitudinal observational study of a population-based cohort of RA patients, it has been demonstrated that the combination infliximab plus leflunomide present the same efficacy and tolerance profile as the combination MTX plus infliximab. ${ }^{61}$ The combination of infliximab with other DMARDs has also been studied, with the same profile of efficacy and tolerability as the infliximab and MTX combination. ${ }^{59-61}$ However, the effects of such combinations on ATI formation are not known.

\section{Safety of infliximab in RA patients}

The three TNF $\alpha$ blockers, including infliximab, have proven to be well tolerated in their clinical development programs. Additional information about the safety profiles of infliximab was provided by a large placebo-controlled trial, the START study (Safety Trial for Rheumatoid Arthritis with Remicade infliximab Therapy), whose aim was to assess the safety of infliximab treatment, ${ }^{63}$ and by postmarketing surveillance.

\section{Infusions reactions}

During and after intravenous administration of infliximab, infusions reactions can occur, as with other foreign protein-derived treatments. Infusion reactions during infusion or in the first 24 hours afterwards are defined as acute reactions. ${ }^{53}$ The majority occur during or in the first 2 hours after infusion, and include headaches flushing, fever, chills and, more rarely, urticaria, dyspnea or hypotension. Delayed reactions are those occurring between 24 hours and 14 days after infusion, most after 5 to 7 days. Mild to moderate infusion reactions may occur in up to $20 \%$ of patients and many can be treated by slowing the rate of infusion. ${ }^{63}$ More severe infusion reactions occur in $2 \%$ to $3 \%$ of patients and may lead to discontinuation of therapy. ${ }^{64}$ The presence of ATI increases the incidence of infusion reactions. ${ }^{49}$ In RA, treatment with infliximab without MTX is an independent risk factor for development of infusion reactions: $16 \%$ of patients with MTX developed infusion reactions compared to $40 \%$ without MTX. ${ }^{53}$

\section{Infections}

Infections are the main adverse event reported with the use of TNF blockers, with a spectrum of pathogens ranging from common bacteria to more opportunistic organisms such as Mycobacterium tuberculosis (tuberculosis).,64 The risk of infections has been analyzed in the large START study, ${ }^{63}$ which included 1084 RA patients, randomized into 3 groups: MTX with placebo, or with infliximab, $3 \mathrm{mg} / \mathrm{kg}$ and $10 \mathrm{mg} /$ $\mathrm{kg}$. At week 22, taking account of corticosteroid treatment, the relative risk (RR) for developing a serious infection was $2.0(95 \%$ CI $0.8-5)$ in combined group of patients receiving infliximab. In the $3 \mathrm{mg} / \mathrm{kg}$ group, the RR of serious infections was 1 (95\% CI 0.3-3.1), increasing up to 3.1 (95\% CI $1.2-7.9, \mathrm{p}=0.013)$ in the $10 \mathrm{mg} / \mathrm{kg}$ group. The most common infectious adverse event was respiratory tract infections. ${ }^{65,66}$ In a meta-analysis published in 2006 by Bongartz et al ${ }^{67}$ the pooled odd ratios for serious infections based on 3493 and 1512 patients who had received anti-TNF $\alpha$ antibody or placebo, respectively, was 2.0 (95\% CI 1.3-3.1) for anti-TNF antibody therapies. This risk of infections is enhanced by the presence of pre-existing infections, long-standing RA, extra-articular manifestations, comorbidities and prednisone therapy. ${ }^{64}$ The risk increases with high dose therapy of infliximab. ${ }^{63}$ However, the frequency of infections is also 
increased in RA patients without biological treatment, compared to healthy controls. ${ }^{68}$

Tuberculosis (TB) is the most frequent opportunistic infection that has been reported with TNF $\alpha$ antagonists. During the first years following the launch of infliximab, postmarketing surveillance in Crohn's and rheumatoid diseases reported 70 cases of TB with some clinical characteristics: the median interval between the start of infliximab and the onset of TB was short, about 12 weeks; the median number of infusions until diagnosis of TB was $3 ; 40 \%$ of the patients had extra-pulmonary disease, 17 with a disseminated disease ${ }^{69}$ According to these data, it was suggested that infliximab was associated with the development of TB. Most of these TB infections occurred in the first 6 to 8 months of use, although a more variable latency period was observed if etanercept was used compared with infliximab. This chronology suggests reactivation of latent TB with the use of anti-TNF antibodies. ${ }^{64,69-71}$ Now there is an emerging consensus for a 5- to 10-fold increased risk of TB reactivation by anti-TNF antibodies but no or only a slightly increased risk of reactivation is associated with the use of the anti-TNF soluble receptor etanercept. ${ }^{64,71}$ TNF $\alpha$ plays a role in host defence against $M$. tuberculosis, notably in stimulating the granulomatous inflammation necessary for the containment and sequestration of these pathogens. ${ }^{70-73}$ Anti-TNF $\alpha$ antibodies are able to disrupt the integrity of granulomas and exacerbate TB infections. Recommendations for the diagnosis and treatment of latent and active TB in patients treated with anti-TNF $\alpha$ agents have emerged. ${ }^{7-77}$ These guideless include the screening methods to be used in these patients and the prophylactic treatments. Adherence to the recommendations is able to reduce the reactivation of latent TB. ${ }^{78}$ Some opportunistic infections have also been reported with the use of infliximab, including histoplasmosis, listeriosis, pulmonary, aspergillosis and pneumocystis carinii pneumonia. ${ }^{5,64}$

\section{Malignancies and lymphomas}

The second major concern has been malignancies. Spontaneous postmarketing surveillance identified a number of cases of lymphoma under anti-TNF $\alpha$ antagonists. The FDA's postmarketing adverse event surveillance system collected and published 26 cases of lymphoma, 18 patients on etanercept and 8 on infliximab. ${ }^{79}$ The estimated lymphoma rate among patients was evaluated to be 6.6 cases in 100000 for those being treated with infliximab. The majority of cases were Non-hodgkin's lymphomas and the median interval between the initiation of anti-TNF $\alpha$ antagonists and the development of lymphoma was short, only 8 weeks. ${ }^{79}$ This rapidity of lymphoma development raises the possibility that the anti-TNF agents might reveal a latent lympho-proliferative disorder. Others reports have also suggested an increased frequency of lymphomas in patients treated with anti-TNF antibodies: In a meta-analysis of malignancies under anti-TNF $\alpha$ antibodies, the pooled OR was estimated to be 3.3 (95\% CI 1.2-9.1) and the risk was higher in patients treated with higher doses than in those receiving lower doses of monoclonal antibodies. ${ }^{67}$ However, the relationship between anti-TNF blockers and the appearance of lymphoma is not clear. The risk of lymphoma is increased in RA patients without anti-TNF blockers, with and without MTX. ${ }^{80,81}$ The standardized incidence ratio (SIR) for lymphoma was calculated from the national databank for rheumatic disease in the US. In patients with RA, the overall SIR for lymphoma was 1.9 (95\% CI 1.3-2.7), whereas SIR for biological treatments was 2.9 (95\% CI 1.4-4.5). The SIR was $2.6(95 \%$ CI 1.4-4.5) for the use of infliximab, 1.7 for the use of MTX and 1.0 for RA patients not receiving MTX or biologicals. ${ }^{80}$ There is also strong evidence that the increase risk of lymphoma in RA patients is related to disease activity itself, independently of treatments. ${ }^{82}$ However, eight cases of a rare cancer, hepatosplenic T-cell lymphoma (HSTL), were recently described in young patients with inflammatory bowel disease treated by infliximab and concomitant immunosuppression. ${ }^{83}$ Treatment with infliximab necessitates a close monitoring of the patients.

For solid cancers, no overall increased risk has been reported in registry studies. However, an increase of skin cancers has been observed with biologics ${ }^{67,81}$ and the skin should be carefully watched.

Taken together, the data do not support an increased risk for solid cancer, except for the skin, but a slightly increased risk for lymphoma for patients receiving anti-TNF agents.

\section{Demyelinating diseases}

Multiple sclerosis (MS), optic neutitis and others forms of demyelinating neurological dysfunction have been reported with use of anti-TNF blockers. ${ }^{64,84,85}$ Observed adverse events include new onset and exacerbation worsening of pre-existing demyelinating diseases. Other than a prior history of demyelinization disease, no predictive factor has been identified. Partial or complete resolution was obtained with cessation of anti-TNF $\alpha$ therapy. The mechanisms that could explain such neurological events remain unclear. Therefore, it is strongly recommended that the anti-TNF $\alpha$ treatments should be stopped when neurological events occur, and strictly avoided in patients with pre-existing demyelination diseases. 
Peripheral neuropathy with varying degrees of motor and sensory involvement were also described in RA patients receiving infliximab. ${ }^{85}$

\section{Drug-induced auto-immunity}

Increased frequency of auto-antibodies has been reported after treatment with anti-TNF, the frequency being greater with infliximab. ${ }^{86}$ In the ATTRACT study, $23 \%$ of patients developed antinuclear antibodies (ANA) and 16\% became positive for anti double-stranded DNA (anti-dsDNA) antibodies. ${ }^{22}$ In the ASPIRE study, 39.6\% and $34.3 \%$ of patients receiving infliximab 3 and $6 \mathrm{mg} / \mathrm{kg}$, respectively, became positive for ANAs. ${ }^{26}$ However, in clinical practice, the development of these antibodies is not associated with the occurrence of systemic auto-immune diseases. ${ }^{87}$

\section{Other side effects}

Anti-TNF $\alpha$ therapies have been associated with congestive heart failure and these biological treatments are contraindicated in patients with a history of NYHA III or IV heart failure. ${ }^{74,88}$ An increase in the liver function test, and pancytopenia, has also been associated with anti-TNFo use ${ }^{64}$ Congenital anomalies have recently been observed in children born to mothers taking TNF antagonist. ${ }^{89}$ Anti-TNF antagonists must be stopped before pregnancy.

\section{Conclusion}

After more than 10 years of commercialization, infliximab is a leading treatment of RA, with a good efficacy and high tolerance. Infliximab is the only licensed TNF antagonist given by infusion, enabling dose adjustment and, for some patients, some rescue of response failure. The favorable results with infliximab use opened the way for the development of new anti-TNF biodrugs and for the use of new biological agents in RA treatment. Today, patients with secondary response failure to one anti-TNF $\alpha$ drug could benefit from switching to another anti-TNF $\alpha$ drug or another biological. ${ }^{90}$ However, the use of infliximab, like the other anti-TNFs, is associated with an increase in side effects, especially infections, and close monitoring of the treated patients is needed.

\section{Disclosures}

The author discloses no conflicts of interest.

\section{References}

1. Lundy SK, Sarkar S, Tesmer LA, Fox D. Cells of the synovium in rheumatoid arthritis. T lymphocytes. Arthritis Res Ther. 2007;9:202.

2. Choy EH, Panayi GS. Cytokine pathways and joint inflammation in rheumatoid arthritis. $N$ Engl J Med. 2001;344:907-916.
3. Feldmann M, Brennan FM, Maini RN. Role of cytokines in rheumatoid arthritis. Annu Rev Immunol. 1996;14:397-440.

4. Furst DE, Breedveld FC, Kalden JR, et al. Updated consensus statement on biological agents for the treatment of rheumatic diseases, 2007. Ann Rheum Dis. 2007;66 Suppl 3:iii2-iii22.

5. Toussirot E, Wendling D. The use of TNF-alpha blocking agents in rheumatoid arthritis: an update. Expert Opin Pharmacother. 2007;8:2089-2107.

6. Maini SR. Infliximab treatment of rheumatoid arthritis. Rheum Dis Clin North Am. 2004;30:329-347.

7. Dain L, Braun-Moscovici Y, Baum E, Nahir AM, Hoffer E. Modification of neutrophil function by plasma of rheumatoid arthritis patients treated with infliximab. Clin Exp Rheumatol. 2006;24:38-44.

8. Tracey D, Klareskog L, Sasso EH, Salfeld JG, Tak PP. Tumor necrosis factor antagonist mechanisms of action: a comprehensive review. Pharmacol Ther. 2008;117:244-279.

9. Eissner G, Kolch W, Scheurich P. Ligands working as receptors: reverse signaling by members of the TNF superfamily enhance the plasticity of the immune system. Cytokine Growth Factor Rev. 2004;15:353-366.

10. Catrina AI, Trollmo C, af Klint E, et al. Evidence that anti-tumor necrosis factor therapy with both etanercept and infliximab induces apoptosis in macrophages, but not lymphocytes, in rheumatoid arthritis joints: extended report. Arthritis Rheum. 2005;52:61-72.

11. Wijbrandts CA, Remans PH, Klarenbeek PL, et al. Analysis of apoptosis in peripheral blood and synovial tissue very early after initiation of infliximab treatment in rheumatoid arthritis patients. Arthritis Rheum. 2008;58:3330-3339.

12. Van Roon JA, Bijlsma JW, Lafeber FP. Diversity of regulatory T cells to control arthritis. Best Pract Res Clin Rheumatol. 2006;20:897-913.

13. Sarkar S, Fox DA. Regulatory T cell defects in rheumatoid arthritis. Arthritis Rheum. 2007;56:710-713.

14. Ehrenstein MR, Evans JG, Singh A, et al. Compromised function of regulatory T cells in rheumatoid arthritis and reversal by anti-TNF alpha therapy. J Exp Med. 2004;200:277-285.

15. Valencia X, Stephens G, Goldbach-Mansky R, Wilson M, Shevach EM, Lipsky PE. TNF downmodulates the function of human CD4+CD25hi T-regulatory cells. Blood. 2006;108:253-261.

16. Bayry J, Sibéril S, Triebel F, Tough DF, Kaveri SV. Rescuing CD4+CD25+ regulatory T-cell functions in rheumatoid arthritis by cytokine-targeted monoclonal antibody therapy. Drug Discov Today. 2007; $12: 548-552$.

17. Van den Berg WB, van Lent PL, Joosten LA, Abdollahi-Roodsaz S, Koenders MI. Amplifying elements of arthritis and joint destruction. Ann Rheum Dis. 2007;66 Suppl 3:iii45-iii8.

18. Boyce BF, Xing L. Biology of RANK, RANKL, and osteoprotegerin. Arthritis Res. 2007;9 Suppl 1:S1 (doi:10.1186/ar2165).

19. Gengenbacher M, Sebald HJ, Villiger PM, Hofstetter W, Seitz M. Infliximab inhibits bone resorption by circulating osteoclast precursor cells in patients with rheumatoid arthritis and ankylosing spondylitis. Ann Rheum Dis. 2008;67:620-624.

20. Chopin F, Garnero P, le Henanff A, et al. Long-term effects of infliximab on bone and cartilage turnover markers in patients with rheumatoid arthritis. Ann Rheum Dis. 2008;67:353-357.

21. Maini RN, Breedveld FC, Kalden JR, et al. Therapeutic efficacy of multiple intravenous infusions of anti-tumor necrosis factor alpha monoclonal antibody combined with low-dose weekly methotrexate in rheumatoid arthritis. Arthritis Rheum. 1998;41:1552-1563.

22. Markham A, Lamb HM. Infliximab: a review of its use in the management of rheumatoid arthritis. Drugs. 2000;59:1341-1359.

23. Maini R, St Clair EW, Breedveld F, et al. Infliximab (chimeric antitumour necrosis factor alpha monoclonal antibody) versus placebo in rheumatoid arthritis patients receiving concomitant methotrexate: a randomised phase III trial. Lancet. 1999;354:1932.

24. Lipsky PE, van der Heijde DM, St Clair EW, et al; Anti-Tumor Necrosis Factor Trial in Rheumatoid Arthritis with Concomitant Therapy Study Group. Infliximab and methotrexate in the treatment of rheumatoid arthritis. N Engl J Med. 2000;343:1594-1602. 
25. Maini RN, Breedveld FC, Kalden JR, et al; Anti-Tumor Necrosis Factor Trial in Rheumatoid Arthritis with Concomitant Therapy Study Group. Sustained improvement over two years in physical function, structural damage, and signs and symptoms among patients with rheumatoid arthritis treated with infliximab and methotrexate. Arthritis Rheum. 2004;50:1051-1065.

26. St Clair EW, van der Heijde DM, Smolen JS, et al; Active-Controlled Study of Patients Receiving Infliximab for the Treatment of Rheumatoid Arthritis of Early Onset Study Group. Combination of infliximab and methotrexate therapy for early rheumatoid arthritis: a randomized, controlled trial. Arthritis Rheum. 2004;50:3432-3434.

27. Goekoop-Ruiterman YP, de Vries-Bouwstra JK, Allaart CF, et al. Clinical and radiographic outcomes of four different treatment strategies in patients with early rheumatoid arthritis (the BeSt study): a randomized, controlled trial. Arthritis Rheum. 2005;52:3381-3390.

28. Allaart CF, Goekoop-Ruiterman YP, de Vries-Bouwstra JK, Breedveld FC, Dijkmans BA; FARR study group. Aiming at low disease activity in rheumatoid arthritis with initial combination therapy or initial monotherapy strategies: the BeSt study. Clin Exp Rheumatol. 2006;24 Suppl 43:S77-S82.

29. van der Bijl AE, Goekoop-Ruiterman YPM, de Vries-Bouwstra JK, et al. Infliximab and methotrexate as induction therapy in patients with early rheumatoid arthritis. Arthritis Rheum. 2007;56:2129-2134.

30. Van der Kooij SM, le Cessie S, Goekoop-Ruiterman YP, et al. Clinical and radiological efficacy of initial versus delayed treatment with infliximab plus methotrexate in patients with early rheumatoid arthritis. Ann Rheum Dis. 2008. doi :10.1136/ard.2008.093294.

31. Nawata M, Saito K, Nakayamada S, Tanaka Y. Discontinuation of infliximab in rheumatoid arthritis patients in clinical remission. Mod Rheumatol. 2008;18:460-464.

32. Smolen JS, Han C, Bala M, et al; ATTRACT Study Group. Evidence of radiographic benefit of treatment with infliximab plus methotrexate in rheumatoid arthritis patients who had no clinical improvement: a detailed subanalysis of data from the anti-tumor necrosis factor trial in rheumatoid arthritis with concomitant therapy study. Arthritis Rheum. 2005;52:1020-1030.

33. Smolen JS, Van Der Heijde DM, St Clair EW; Active-Controlled Study of Patients Receiving Infliximab for the Treatment of Rheumatoid Arthritis of Early Onset (ASPIRE) Study Group. Predictors of joint damage in patients with early rheumatoid arthritis treated with high-dose methotrexate with or without concomitant infliximab: results from the ASPIRE trial. Arthritis Rheum. 2006;54:702-710.

34. Smolen JS, Han C, van der Heijde DM, et al. Radiographic changes in rheumatoid arthritis patients attaining different disease activity states with methotrexate monotherapy and infliximab plus methotrexate: the impacts of remission and TNF-blockade. Ann Rheum Dis. 2008. doi 10.1136/ard.2008.090019.

35. Quinn MA, Conaghan PG, O'Connor PJ, et al. Very early treatment with infliximab in addition to methotrexate in early, poor-prognosis rheumatoid arthritis reduces magnetic resonance imaging evidence of synovitis and damage, with sustained benefit after infliximab withdrawal: results from a twelve-month randomized, double-blind, placebo-controlled trial. Arthritis Rheum. 2005;52:27-35.

36. Durez P, Malghem J, Toukap AN, et al. Treatment of early rheumatoid arthritis. A randomized magnetic resonance imaging study comparing the effects of methotrexate alone, methotrexate in combination with infliximab and methotrexate in combination with intravenous pulse methylprednisolone. Arthritis Rheum. 2007;56:3919-3927.

37. Taylor PC, Steuer A, Gruber J, et al. Ultrasonographic and radiographic results from a two-year controlled trial of immediate or one-year-delayed addition of infliximab to ongoing methotrexate therapy in patients with erosive early rheumatoid arthritis. Arthritis Rheum. 2006;54:47-53.

38. Stern R, Wolfe F. Infliximab dose and clinical status: results of 2 studies in 1642 patients with rheumatoid arthritis. $J$ Rheumatol. 2004;31:1538-1545.

39. Etemad L, Yu EB, Wanke LA. Dose adjustment over time of etanercept and infliximab in patients with rheumatoid arthritis. Manag Care Interface. 2005;18:21-27.
40. Vander Cruyssen B, Van Looy S, Wyns B, et al. Four-year follow-up of infliximab therapy in rheumatoid arthritis patients with long-standing refractory disease: attrition and long-term evolution of disease activity. Arthritis Res Ther. 2006;8:R112.(doi 10.1186/AR2001).

41. Van Looy S, Vander Cruyssen B, Meeus J, et al. Prediction of dose escalation for rheumatoid arthritis patients under infliximab treatment. Engineering Application Artifical Intelligence. 2006;19:819-828.

42. Rahman MU, Strusberg I, Geusens P, et al. Double-blinded infliximab dose escalation in patients with rheumatoid arthritis. Ann Rheum Dis. 2007;66:1233-1238.

43. Ariza-Ariza R, Navarro-Sarabia F, Hernández-Cruz B, RodríguezArboleya L, Navarro-Compán V, Toyos J. Dose escalation of the antiTNF-alpha agents in patients with rheumatoid arthritis. A systematic review. Rheumatology (Oxford). 2007;46:529-532.

44. Buch MH, Bingham SJ, Bryer D, Emery P. Long-term infliximab treatment in rheumatoid arthritis: subsequent outcome of initial responders. Rheumatology (Oxford). 2007;46:1153-1156.

45. Ducoulombier V, Solau E, Coquerelle P, et al. Long-term results of infliximab therapy in rheumatoid arthritis: experience acquired by the NorthPas-de-Calais hospital network. Joint Bone Spine. 2007;74:56-59.

46. Figueiredo IT, Morel J, Sany J, Combe B. Maintenance and tolerability of infliximab in a cohort of 152 patients with rheumatoid arthritis. Clin Exp Rheumatol. 2008;26:18-23.

47. Flendrie M, Creemers MC, van Riel PL. Titration of infliximab treatment in rheumatoid arthritis patients based on response patterns. Rheumatology (Oxford). 2007;46:146-149.

48. Zintzaras E, Dahabreh IJ, Giannouli S, Voulgarelis M, Moutsopoulos HM. Infiximab and methotrexate in the treatment of rheumatoid arthritis : a systematic review and meta-analysis of dosage regimens. J Clinthera. 2008;11:1939-1954.

49. Baert F, Noman M, Vermeire S, et al. Influence of immunogenicity on the long-term efficacy of infliximab in Crohn's disease. N Engl J Med. 2003;348:601-608.

50. Radstake TR, Svenson M, Eijsbouts AM, et al. Formation of antibodies against infliximab and adalimumab strongly correlates with functional drug levels and clinical responses in rheumatoid arthritis. Ann Rheum Dis. 2008. doi:10.1136/ard.2008.092833.

51. Maser EA, Villela R, Silverberg MS, Greenberg GR. Association of trough serum infliximab to clinical outcome after scheduled maintenance treatment for Crohn's disease. Clin Gastroenterol Hepatol. 2006;4:1248-1254.

52. Klotz U, Teml A, Schwab M. Clinical pharmacokinetics and use of infliximab. Clin Pharmacokinet. 2007;46:645-660.

53. Lecluse LL, Piskin G, Mekkes JR, Bos JD, de Rie MA. Review and expert opinion on prevention and treatment of infliximab-related infusion reactions. Br J Dermatol. 2008. doi10.1111/J.1365-2133.2008.08728x.

54. Kapetanovic MC, Larsson L, Truedsson L, Sturfelt G, Saxne T, Geborek P. Predictors of infusion reactions in patients with arthritis. Arthritis Res Ther. 2006;8:R131.

55. Vermeire S, Noman M, van Assche G, Baert F, D'Haens G, Rutgeerts P. Effectiveness of concomitant immuno-suppressive therapy in suppressing the formation of antibodies to infliximab in crohn disease. Gut. 2007;56:1226-1231.

56. Kiely PD, Johnson DM. Infliximab and leflunomide combination therapy in rheumatoid arthritis: an open-label study. Rheumatology. 2002;41:631-637.

57. Bingham S, Bush MH, Kerr MA, Emery P, Valadeo Barcelos AT. Induction of antinuclear antibodies in patients with rheumatoid arthritis treated with Infliximab and leflunomide. Arthritis Rheum. 2004;50:4072-4073.

58. Hansen KE, Cush J, Singhal A, et al. The safety and efficacy of Leflunomide in combination with Infliximab in rheumatoid arthritis. Arthritis Rheum. 2004;51:228-232.

59. Perdriger A, Mariette X, Kuntz JL, et al; Club Rheumatismes et Inflammation.Safety of infliximab used in combination with leflunomide or azathioprine in daily clinical practice. J Rheumatol. 2006;33(5):865-869. 
60. Hyrich KL, Symmons DP, Watson KD, Silman AJ; British Society for Rheumatology Biologics Register. Comparison of the response to infliximab or etanercept monotherapy with the response to cotherapy with methotrexate or another disease-modifying antirheumatic drug in patients with rheumatoid arthritis: results from the British Society for Rheumatology Biologics Register. Arthritis Rheum. 2006;54:1786-1794.

61. Finckh A, Dehler S, Gabay C. The effectiveness of leflunomide as a co-therapy of tumour necrosis factor inhibitors in rheumatoid arthritis: a population-based study. Ann Rheum Dis. 2009;68:33-39.

62. Kalden JR, Nüßlein HG, Wollenhaupt J, Burmester GR, Krüger K, Antoni C. Combination treatment with infliximab and leflunomide in patients with active rheumatoid arthritis: safety and efficacy in an open-label clinical trial. Clin Exp Rheumatol. 2008;26:834-840.

63. Westhovens R, Yocum D, Han J, et al; START Study Group. The safety of infliximab, combined with background treatments, among patients with rheumatoid arthritis and various comorbidities: a large, randomized, placebo-controlled trial. Arthritis Rheum. 2006;54:1075-1086.

64. Cush JJ. Safety overview of new disease-modifying antirheumatic drugs. Rheum Dis Clin North Am. 2004;30:237-255.

65. Listing J, Strangfeld A, Kary S, et al. Infections in patients with rheumatoid arthritis treated with biologic agents. Arthritis Rheum. 2005;52:3403-3412.

66. Kroesen S, Widmer AF, Tyndall A, Hasler P. Serious bacterial infections in patients with rheumatoid arthritis under anti-TNF-alpha therapy. Rheumatology. 2003;42:617-621.

67. Bongartz T, Sutton AJ, Sweeting MJ, Buchan I, Matteson EL, Montori V. Anti-TNF antibody therapy in rheumatoid arthritis and the risk of serious infections and malignancies: systematic review and meta-analysis of rare harmful effects in randomized controlled trials. JAMA. 2006;295:2275-2285.

68. Doran MF, Crowson CS, Pond GR, O'Fallon WM, Gabriel S. Frequency of infection in patients with rheumatoid arthritis compared with controls: a population-based study. Arthritis Rheum. 2002;46:2287-2293.

69. Keane J, Gershon S, Wise RP, et al. Tuberculosis associated with infliximab, a tumor necrosis factor alpha-neutralizing agent. $N$ Engl J Med. 2001;345:1098-1104.

70. Gardam MA, Keystone EC, Menzies R, et al. Anti-tumour necrosis factor agents and tuberculosis risk: mechanisms of action and clinical management. Lancet. 2003;3:148-155.

71. Ehlers S. Tumor necrosis factor and its blockade in granulomatous infections: differential modes of action of infliximab and etanercept? Clin Infect Dis. 2005;41 Suppl 3:S199-S203.

72. Hooper M, Chi E. Anti-TNF antibodies associated with different risk of latent tuberculosis activation. Am J Med. 2006;119:639-646.

73. Harris J, Hope JC, Keane J. Tumor necrosis factor blockers influence macrophage responses to Mycobacterium tuberculosis. J Infect Dis. 2008; 198:1842-1850.

74. Hochberg MC, Lebwohl MG, Plevy SE, Hobbs KF, Yocum DE; The benefit/risk profile of TNF-blocking agents: findings of a consensus panel. Semin Arthritis Rheum. 2005;34:819-836.

75. Winthrop KL. Risk and prevention of tuberculosis and other serious opportunistic infections associated with the inhibition of tumor necrosis factor. Nat Clin Pract Rheumatol. 2006;2:602-610.
76. Lalvani A, Millington KA. Screening for tuberculosis infection prior to initiation of anti-TNF therapy. Autoimmun Rev. 2008;8:147-152.

77. Hamdi H, Mariette X, Godot V, et al; RATIO (Recherche sur AntiTNF et Infections Opportunistes) Study Group. Inhibition of antituberculosis T-lymphocyte function with tumour necrosis factor antagonists. Arthritis Res Ther. 2006;8:R114.

78. Gomez-Reino JJ, Carmona L, Descalzo; for the biobadaser group. Risk of tuberculosis in patients treated with tumor necrosis factor antagonists due to incomplete prevention of reactivation of latent infection. Arthritis Care Res. 2007;57:756-761.

79. Brown SL, Greene MH, Gershon SK, Edwards ET, Braun MM. Tumor necrosis factor antagonist therapy and lymphoma development: twentysix cases reported to the Food and Drug Administration. Arthritis Rheum. 2002;46:3151-3158.

80. Wolfe F, Michaud K. Lymphoma in rheumatoid arthritis: the effect of methotrexate and anti-tumor necrosis factor therapy in 18,572 patients. Arthritis Rheum. 2004;50:1740-1751.

81. Wolfe F, Michaud K. Biologic treatment of rheumatoid arthritis and the risk of malignancy: analyses from a large US observational study. Arthritis Rheum. 2007;56:2886-2895.

82. Baecklund E, Iliadou A, Askling J, et al. Association of chronic inflammation, not its treatment, with increased lymphoma risk in rheumatoid arthritis. Arthritis Rheum. 2006;54:692-701.

83. Beyer M, Steinhoff M, AnagnostopoulosI, Assaf C, Sterry W. Hepatosplenic T-cell lymphomas and theraphy with TNF-alpha-blocking biologics :a risk for psoriasis patients? J Dtsch Dermatol Ges. 2009 Jan 12. [epub ahead of print].

84. Robinson WH, Genovese MC, Moreland LW. Demyelinating and neurologic events reported in association with tumor necrosis factor alpha antagonism: by what mechanisms could tumor necrosis factor alpha antagonists improve rheumatoid arthritis but exacerbate multiple sclerosis? Arthritis Rheum. 2001;44:1977-1983.

85. Stubgen JP. Tumor necrosis factor-alpha antagonists and neuropathy. Muscle Nerve. 2008;37:81-92.

86. Bacquet-Deschryver H, Jouen F, Quillard M, et al. Impact of three anti-TNFalpha biologics on existing and emergent autoimmunity in rheumatoid arthritis and spondylarthropathy patients. J Clin Immunol. 2008;28:445-455.

87. Ramos-Casals M, Brito-Zerón P, Muñoz S, et al. Autoimmune diseases induced by TNF-targeted therapies: analysis of 233 cases. Medicine. 2007;86:242-251

88. Lisman KA, Stetson SJ, Koerner MM, Farmer JA, Torre-Amione G. The role of tumor necrosis factor alpha blockade in the treatment of congestive heart failure. Congest Heart Fail. 2002;8:275-279.

89. Carter JD, Ladhani A, Ricca LR, Valeriano J, Vasey FB. A safety assessment of tumor necrosis factor antagonists during pregnancy: a review of the food and drug administrationdatabase. J Rheumatol. 2008. doi:10.3899/jrheumotol.080545.

90. Lutt JR, Deodhar A. Rheumatoid arthritis: strategies in the management of patients showing an inadequate response to TNF alpha antagonists. Drugs. 2008;68:591-606.
Biologics: Targets \& Therapy

\section{Publish your work in this journal}

Biologics: Targets \& Therapy is an international, peer-reviewed journal focusing on the patho-physiological rationale for and clinical application of Biologic agents in the management of autoimmune diseases, cancers or other pathologies where a molecular target can be identified. This journal is indexed on PubMed Central, CAS,

\section{Dovepress}

EMBase, Scopus and the Elsevier Bibliographic databases. The manuscript management system is completely online and includes a very quick and fair peer-review system, which is all easy to use. Visit http://www.dovepress.com/testimonials.php to read real quotes from published authors. 